\title{
Usefulness of an early warning score as an early predictor of clinical deterioration in hospitalized children
}

\author{
Magali Elencwajg, M.D. ${ }^{a}$, Nicolás A. Grisolía, M.D. ${ }^{a}$, Claudia Meregalli, M.D. ${ }^{a}$, \\ Micaela A. Montecuco, M.D. ${ }^{a}$, María V. Montiel, M.D. ${ }^{a}$, Gabriela M. Rodríguez, M.D. ${ }^{a}$ \\ and Carla C. Serviddio, M.D. ${ }^{a}$
}

\begin{abstract}
Introduction. The early detection of clinical deterioration in hospitalized patients helps to improve the quality of care. The pediatric early warning score (PEWS) system predicts such deterioration in the first 24 hours of administration. Prior studies support the use of these tools.

Objective. Toassess the usefulness of theBrighton PEWS (B-PEWS) for the prediction of clinical deterioration among hospitalized children at a children's hospital in the Autonomous City of Buenos Aires.

Population and methods. Cross-sectional study. The medical records of all patients aged 1 month to 18 years admitted to any hospitalization ward between March $1^{\text {st }}$ and August 31 $1^{\text {st }}, 2018$ were included. Predictive outcome measure: B-PEWS score ( $\leq 3$ and $\geq 4$ points). Outcome variable: clinical deterioration in the first 24 hours. Categorical outcome measures were analyzed with the $\chi^{2}$ test and screening values were estimated. The relative risk was used as a measure of association. A ROC curve analysis and an optimal cut-point analysis according to the Youden index were done considering the score in a continuous manner.

Results. A total of 518 medical records were reviewed. Forty patients had clinical deterioration; the B-PEWS score was $\geq 4$ in 37 patients and $\leq 3$ in 3 (relative risk: 56.36; $95 \%$ confidence interval: 17.76-178.89; $p<0.01$ ). Sensitivity: $92.5 \%$; specificity: $88.3 \%$; positive predictive value: $39.8 \%$; negative predictive value: $99.3 \%$; positive likelihood ratio: 7.91 ; negative likelihood ratio: 0.08. AUC: 0.94 (95\% confidence interval: 0.89-0.98).

Conclusion. The B-PEWS demonstrated to be useful to predict clinical deterioration in hospitalized children.

Key words: early warning score, child, patient admission, hospitalization.
\end{abstract}

http: / / dx.doi.org/10.5546/ aap.2020.eng.399

Nicolás A. Grisolía, M.D.: nicolasarielgrisolia@

hotmail.com

Funding:

None.

Conflict of interest: None.

Received: 3-11-2020

Accepted: 6-1-2020
To cite: Elencwajg M, Grisolía NA, Meregalli C, Montecuco MA, et al. Usefulness of an early warning in hospitalized children. Arch Argent Pediatr 2020; 118(6):399-404.

\section{INTRODUCTION}

Hospitalized children are susceptible to developing clinical deterioration during a hospitalization. Physiological and behavioral changes have been described to occur hours before clinical deterioration unfolds. ${ }^{1-4}$

The early detection of this condition in hospitalized patients helps to improve the quality of care. With such early assessment of critically-ill patients, it is possible to determine a timely admission to the pediatric intensive care unit (PICU) or the performance of major procedures. ${ }^{1-4}$

To this end, different pediatric early warning scores (PEWS) that allow a rapid patient assessment have been developed. One of these scoring systems was created by Monaghan et al. at a Brighton hospital in 2005 and is known as the Brighton Pediatric Early Warning Score ( B-PEWS). It allows to predict clinical deterioration based on three aspects: respiratory, cardiovascular, and behavioral items. The B-PEWS assigns a specific score to each item and provides a total sum of 0 to 13 points. Some studies have suggested that this tool allows to detect clinical deterioration in the 24 hours before it becomes patent. ${ }^{1,5,6}$

Multiple prospective and retrospective studies support the use of the B-PEWS at an international level. ${ }^{1-4,6}$ However, there is no evidence at a local level, so the objective of this study was to assess the usefulness of the B-PEWS to predict clinical deterioration in hospitalized children in the setting of a children's hospital located in the Autonomous City of Buenos Aires. 


\section{POPULATION AND METHODS}

This was an observational, cross-sectional study conducted between March $1^{\text {st }}$ and August $31^{\text {st }}, 2018$. The medical records of all patients aged 1 month to 18 years admitted to any hospitalization ward of the Department of Medicine were included. The medical records of patients transferred from other hospital departments or diagnosed with diabetic ketoacidosis were excluded.

The predictive outcome measure was the B-PEWS score at the time of admission dichotomized into a cut-off point of more than or equal to 4 (four) (Table 1). The outcome variable was the presence of clinical deterioration in the first 24 hours of admission (dichotomous, categorical variable), defined as the development of one or more of the following parameters:

- Consultation with the PICU.

- Transfer to the PICU.

- Performance of one or more major procedures: basic and / or advanced cardiopulmonary resuscitation (CPR), two or more volume expansions with crystalloid solutions (saline solution [SS]) or colloid solutions, magnesium sulfate (Mg sulfate) infusion during an asthma attack, high flow nasal cannula (HFNC) use in the case of bronchiolitis, pleural drainage tube (PDT) placement.

- Death.

The investigators reviewed the records of patient course during the first 24 hours of admission and administered the B-PEWS to capture the outcome variable a single time. It should be noted that since this tool has not yet been validated at the study hospital, medical actions taken during the study period were based on the health care team's judgment, not on the resulting score.

Studied outcome measures were described using proportions for categorical outcome measures and mean values with standard deviation or median values with interquartile range $\left(\mathrm{IQR}_{25-75}\right)$ (based on the adjustment to normality using the Kolmogorov-Smirnov test) for continuous outcome measures. Proportions were compared using the $\chi^{2}$ test and also estimating the diagnostic performance values. The relative risk (RR) was used as a measure of association. These values were accompanied by a $p$ value $(p)$, assuming a significance level of $p<0.05$ and a $95 \%$ confidence interval (CI).

An analysis based on the Receiver Operating Characteristic (ROC) curve was done to determine the cut-off point of the B-PEWS with the best discrimination power and considering such score as a continuous outcome measure. The area under the curve (AUC) analysis was done based on the non-parametric method and the optimal cutpoint was established using the Youden index and comparing our results to those reported in the bibliography. The AUC was accompanied by a $95 \% \mathrm{CI}$, as reported by the statistical analysis package (SPSS 21.0.).

The total percentage of clinical deterioration was $37 \%$ in patients with a B-PEWS $\geq 4$; the pre-

TABLE 1. Brighton Pediatric Early Warning Score (B-PEWS)

\begin{tabular}{|c|c|c|c|c|}
\hline & 0 & 1 & 2 & Score \\
\hline Behavior & $\begin{array}{c}\text { Playing/ } \\
\text { appropriate. }\end{array}$ & Sleeping. & Irritable. & $\begin{array}{l}\text { Lethargic/ confused. } \\
\text { Reduced response } \\
\text { to pain. }\end{array}$ \\
\hline Cardiovascular & $\begin{array}{l}\text { Pink or capillary } \\
\text { refill 1-2 seconds. }\end{array}$ & $\begin{array}{l}\text { Pale or capillary } \\
\text { refill } 3 \text { seconds. }\end{array}$ & $\begin{array}{l}\text { Grey or capillary refill } \\
4 \text { seconds. } \\
\text { Tachycardia of } 20 \text { beats } \\
\text { above the upper limit } \\
\text { for age. }\end{array}$ & $\begin{array}{l}\text { Grey and mottled or capillary } \\
\text { refill } 5 \text { seconds or above. } \\
\text { Tachycardia of } 30 \text { beat } \\
\text { above the upper limit for age } \\
\text { or bradycardia. }\end{array}$ \\
\hline Respiratory & $\begin{array}{l}\text { Within normal } \\
\text { parameters, } \\
\text { no retractions. }\end{array}$ & $\begin{array}{l}\text { More than } 10 \text { breaths } \\
\text { above normal parameters, } \\
\text { using accessory muscles, } \\
30 \% \mathrm{FiO}_{2} \text { or } 3 \mathrm{~L} / \mathrm{min}_{2} \text {. }\end{array}$ & $\begin{array}{l}\text { More than } 20 \text { breaths } \\
\text { above normal parameters, } \\
\text { retractions or } 40 \% \mathrm{FiO}_{2} \\
\text { or } 6 \mathrm{~L} / \mathrm{min} \mathrm{O}_{2} .\end{array}$ & $\begin{array}{l}\text { Less than } 5 \text { breaths below } \\
\text { normal parameters, } \\
\text { retractions, grunting, } \\
50 \% \mathrm{FiO}_{2} \text { or } 8 \mathrm{~L} / \mathrm{min}_{2} \text {. }\end{array}$ \\
\hline
\end{tabular}

Two additional points were assigned to the patient who was nebulized within 15 minutes (including continuous nebulizations) and to the one in the post-operative period with persistent vomiting.

From: "Sensitivity of the pediatric early warning score to identify patient deterioration". ${ }^{3}$

The same study ${ }^{3}$ describes vital signs as a reference. 
test likelihood was estimated at $20 \%$ whereas the estimated post-test percentage was $17 \%$, according to the gold standard. ${ }^{2,7}$ The sample size was estimated at 220 subjects (110 in each group). A $95 \% \mathrm{CI}$ and an $80 \%$ power were targeted. The analysis was done with the StatCalc 7.1 software by the CDC. Since no prior pilot test was done and given that this was a merely observational study, the proposed gold standard was maintained, ${ }^{2}$ which was consistent with that implemented in our practice. ${ }^{7}$

\section{Ethical considerations}

Access to the data collected in the study was in accordance with all ethical and legal regulations governing it (Act no. 25326 for the Protection of Personal Information). In accordance with the rules governing research in the setting of facilities dependent on the Government of the Autonomous City of Buenos Aires, the study was approved by the Research Ethics Committee and the Research and Teaching Committee and registered before the Health Research Council of the Government of the Autonomous City of Buenos Aires (No. 378/17).

\section{RESULTS}

A total of 743 medical records were reviewed; of these $225(30 \%)$ were excluded due to missing data. The analysis included 518 medical records of patients admitted to any hospitalization ward between March and August 2018 (Figure 1).

FIGURE 1. Flow chart of study population distribution

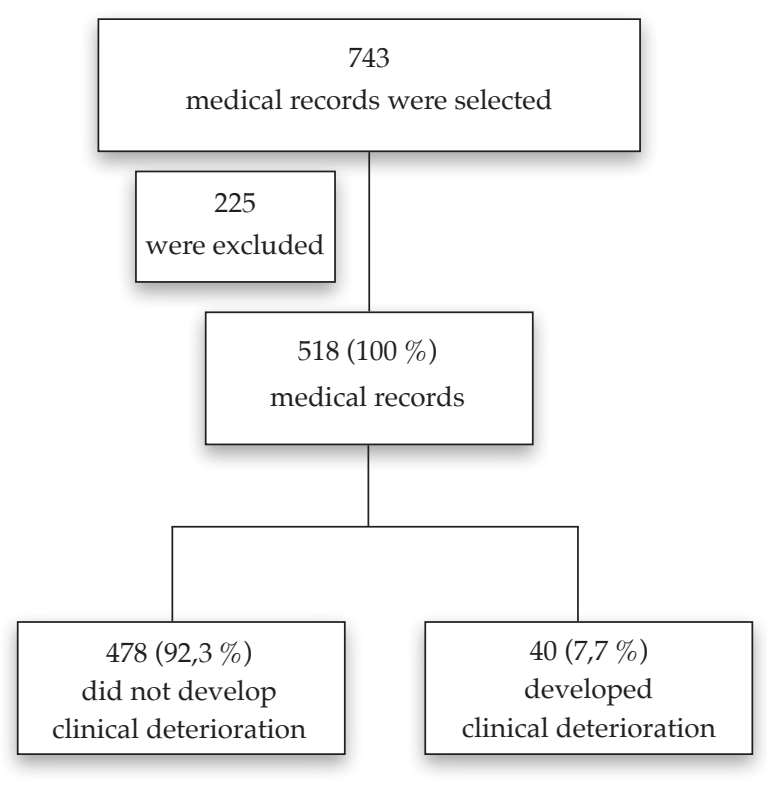

The most common diagnoses at the time of admission were respiratory conditions $(44.98 \%)$, followed by skin infections $(10.04 \%)$ and gastrointestinal conditions $(8.69 \%)$. The assessment of the study population based on the dichotomized B-PEWS indicated that 423 patients $(81.7 \%)$ had a score of 0 to 3 points and 95 $(18.3 \%), 4$ points or more. The median age and the sex distribution were similar in both groups. The frequency of clinical deterioration was $0.7 \%$ and $39.8 \%$, respectively (Table 2 ).

Out of the total sample, 40 patients $(7.7 \%)$ developed clinical deterioration in the first 24 hours of admission. Table 3 describes the clinical course of the study population.

The analysis of the PEWS' prognostic value dichotomized into $\leq 3$ versus $\geq 4$ showed a relative risk of having an outcome of interest in the greater severity group of 56.36 (95\% CI: 17.76$178.89 ; p<0.01)$ compared to the lower severity group. The diagnostic performance showed a sensitivity of $92.5 \%$, a specificity of $88.3 \%$, a positive predictive value of $39.8 \%$, a negative predictive value of $99.3 \%$, a positive likelihood ratio of 7.91, and a negative likelihood ratio of 0.08 . The ROC curve analysis showed an AUC of 0.94 (95 \% CI: 0.89-0.98). The optimal cut-point was estimated at 4 (Youden index: 0.8) (Figure 2).

\section{DISCUSSION}

The use of the system developed by Monaghan (B-PEWS $)^{5}$ requires only brief health care staff training and can be easily administered in every hospital department. Several studies concluded that administering the B-PEWS would potentially improve communication among health care professionals for the benefit of the patient involved..$^{5,8,9}$ It would also improve the medical records of hospitalized patients at the health center where it is implemented.

The results of our study are consistent with the bibliography. The optimal cut-point (4) obtained using the Youden index was similar to the cutoff value reported in the studies by Miranda, ${ }^{2}$ Monaghan, ${ }^{5}$ Oldroyd, ${ }^{4}$ and Tucker. ${ }^{8}$

In relation to diagnostic precision values, the B-PEWS showed adequate sensitivity, specificity, and negative predictive value, which was consistent with the little proportion of clinical deterioration observed in the B-PEWS values that were $\leq 3$. The positive predictive value was smaller because the analysis was done by dichotomizing the score (B-PEWS $\leq 3$ and $\geq 4$ ), which was able to predict clinical deterioration 
in a more effective manner with higher scores. Anyway, it was also observed that a higher score correlated to a higher percentage of clinical deterioration, which indicates that the B-PEWS is highly useful as a baseline screening clinical tool. These results are in agreement with those reported by Tucker, ${ }^{8}$ Miranda, ${ }^{2}$ and Rosman. ${ }^{10}$ It is believed that this is related to similarities in study design and sample.

It would also be important to implement these warning systems in our setting and improve them based on the population characteristics. In 2016, in Brazil, the B-PEWS was translated into Portuguese. ${ }^{11}$ The following year, the same

TABLE 2. Population description based on the dichotomized Brighton Pediatric Early Warning Score

\begin{tabular}{lcc}
\hline B-PEWS & B-PEWS $\leq 3$ & B-PEWS $\geq 4$ \\
\hline N subgroups $^{* 1}$ & $423(81.7 \%)$ & $95(18.3 \%)$ \\
Age $^{* 2}$ & $2\left(\mathrm{IQR}_{25-75} 0.7-6.5\right.$ years $)$ & $2.08\left(\mathrm{IQR}_{25-75} 0.9-6.6\right.$ years $)$ \\
Sex $^{* 3}$ & Male $(52.9 \%)$ & Male $(60.2 \%)$ \\
Most common diagnosis $^{* 3}$ & Respiratory $(36.2 \%)$ & Respiratory $(84.9 \%)$ \\
Clinical deterioration $^{* 3}$ & $3(0.7 \%)$ & $37(39.8 \%)$ \\
\hline
\end{tabular}

B-PEWS: Brighton Pediatric Early Warning Score; N: number of subjects; $\mathrm{IQR}_{25-75}$ : interquartile range;

$\mathrm{FiO}_{2}$ : fraction of inspired oxygen; $\mathrm{O}_{2}$ : oxygen.

${ }^{*}$ The percentage described here was estimated based on the total sample $(\mathrm{N}=518)$.

*2 Expressed as median and interquartile range.

*3 The percentage described here was estimated based on the total number of patients in each subgroup.

TABLE 3. Description of the population's clinical course based on the categorized Brighton Pediatric Early Warning Score

\begin{tabular}{|c|c|c|}
\hline B-PEWS & No. of patients & No. of patients who experienced clinical deterioration ${ }^{* 1}$ \\
\hline 0 to 3 & 423 & $\begin{array}{l}\text { Clinical deterioration: } 3(0.7 \%)^{\star 2} \\
\text { - Consultation with the PICU = } 3 \\
\text { - Transfer to the PICU }=0 \\
\text { - Major procedure }=1 \\
\quad-1 \text { expansion with SS }\end{array}$ \\
\hline 4 to 6 & 76 & $\begin{array}{l}\text { Clinical deterioration: } \mathbf{2 3}(\mathbf{3 0 . 3} \%)^{*_{2}} \\
\text { - Consultation with the PICU = 5 } \\
\text { - Transfer to the PICU }=3 \\
\text { - Major procedure }=20 \\
-7 \text { expansions with SS } \\
-6 \mathrm{HFNC} \\
-3 \mathrm{Mg} \text { sulfate }{ }^{++}\end{array}$ \\
\hline 7 to 8 & 15 & $\begin{array}{l}\text { Clinical deterioration: } 10(67 \%)^{* 2} \\
\text { - Consultation with the PICU }=3 \\
\text { - Transfer to the PICU = } \\
\text { - Major procedure }=9 \\
-5 \text { expansions with SS } \\
-2 \text { PDT } \\
-2 \text { HFNC } \\
\text { - Death }=1\end{array}$ \\
\hline 9 & 4 & $\begin{array}{l}\text { Clinical deterioration: } 4(100 \%)^{* 2} \\
\text { - Consultation with the PICU }=4 \\
\text { - Transfer to the PICU }=3 \\
\text { - Major procedure }=2 \\
-1 \mathrm{HFNC} \\
-1 \mathrm{Mg} \text { sulfate }{ }^{++} \\
-1 \mathrm{CPR}\end{array}$ \\
\hline
\end{tabular}

B-PEWS: Brighton Pediatric Early Warning Score; consultation with the PICU: consultation with the pediatric intensive care unit; transfer to the PICU: transfer to the pediatric intensive care unit; expansion with SS: volume expansion with saline solution; HFNC: high flow nasal cannula; $\mathrm{Mg}$ sulfate ${ }^{++}$: administration of magnesium sulfate; PDT: pleural drainage tube placement; CPR: basic and/or advanced cardiopulmonary resuscitation.

${ }^{*}$ Many patients met more than one clinical deterioration criteria simultaneously.

*2 The percentage described here was estimated based on the total number of patients in each subgroup. 
team conducted a study about the translated and adapted version (B-PEWS-Br) in a Brazilian setting and concluded that it was valid to detect the warning signs of clinical deterioration in studied children, although they clarified the need to conduct multicenter studies for its routine use in hospitalized children. In addition, this study pointed out the difference in the criteria applied by the different studies to define clinical deterioration in studied patients.

Pediatric early warning systems are widely recommended in many countries. ${ }^{12,13}$ In 2013, $85 \%$ of children's facilities in the United Kingdom were using the PEWS. In Argentina, not much evidence has been published about the implementation of these systems. ${ }^{14}$ Hospital Italiano de Buenos Aires published a study in 2016 which concluded that the PEWS had been useful to predict clinical deterioration in patients at risk. ${ }^{15}$ It is important to point out that those results were similar to ours.

However, it should also be noted that the PEWS only allows for the early detection of clinical deterioration. It is necessary to have adequate resources and a standardized rapid response protocol available to effectively take action in relation to the patient. This response protocol will be customized to each health center. ${ }^{12}$ A study conducted in 2008 showed that the implementation of the PEWS in a health center for 8 months was associated with an $83 \%$ reduction $(p=0.01)$ in the rate of late transfers to referral facilities, a $77 \%$ reduction $(p<0.0001)$ in stat calls to the in-house

FIGURE 2. Receiver Operating Characteristic curve analysis

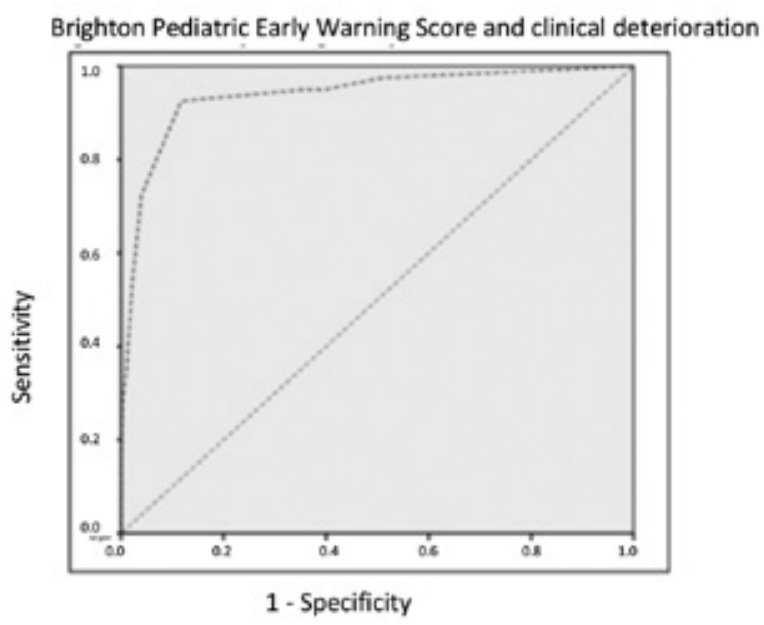

AUC 0.94 [95 \% CI: 0.89-0.98].

Optimal cut-point for the B-PEWS 4 (Youden: 0.8).

AUC: area under the curve; CI: confidence interval. pediatrician, a $64 \%$ reduction $(p<0.0001)$ in stat calls to respiratory therapists, and corroborated a $37 \%$ increase $(p=0.041)$ in the interhospital transfer rate to the PICU. ${ }^{13}$

A significant variation has been observed in terms of the range used to assess the PEWS consecutively. Some studies conducted a timebased assessment, every 4 hours; others, once daily, as needed or based on the resulting score. For this study, it was decided to perform only one measurement in the first 24 hours of patient admission.

Another controversial factor lies in the different criteria used to define clinical deterioration as per the bibliography. Gold, ${ }^{6}$ Tume, ${ }^{12}$ and Miranda ${ }^{2}$ defined it as transfer to the PICU only; Tucker, ${ }^{8}$ as transfer to the PICU and cardiorespiratory arrest; Parshuram, ${ }^{13}$ as transfer to the PICU, volume expansion with crystalloid solutions at a rate of $60 \mathrm{~mL} / \mathrm{kg}, \mathrm{CPR}$, and death.

Early warning systems have been adapted in various manners. However, Chapman ${ }^{16}$ compared several early warning scores and concluded that using these with more complex variables does not improve the outcome.

In our sample, patients transferred from other hospital departments (except for the Emergency Department) were excluded to prevent a selection bias created by the referral of patients with chronic conditions that required only clinical tests. Likewise, patients diagnosed with diabetic ketoacidosis were excluded because this condition was usually managed at the intensive care unit due to its potential severity.

Since $30 \%$ of initially included medical records were lost, this study experienced a strong selection bias. Anyway, it was considered minimized because the estimated sample size was reached, these medical records were not initially analyzed, and, in addition, it was balanced between both groups with and without clinical deterioration.

A potential bias was also due to the mild differences in data because the B-PEWS was administered considering the vital signs written down in the medical records and not on direct patient observation. However, there is evidence of the validity of the estimation of the PEWS based on medical records. ${ }^{12}$

The objective of our study was to assess the usefulness of a specific system, the B-PEWS; however, due to the large variety of published scores and the different results obtained with each, future studies should be conducted to 
assess which is the most adequate score for our population. Local studies with a greater level of evidence are required for the validation and future implementation of the PEWS in the hospital's clinical guidelines based on the context of the hospital where it will be implemented. ${ }^{10}$

\section{CONCLUSION}

The B-PEWS proved to be useful to predict clinical deterioration in hospitalized children in the setting of a children's hospital in the Autonomous City of Buenos Aires.

\section{REFERENCES}

1. Duncan H, Hutchison J, Parshuram CS. The pediatric early warning system score: a severity of illness score to predict urgent medical need in hospitalized children. J Crit Care. 2006; 21(3):271-8.

2. Miranda JO, Camargo CL, Sobrinho CL, Portela DS, et al. Precisión de un puntaje pediátrico de alerta precoz en el reconocimiento de la deterioración clínica. Rev Lat Am Enfermagem. 2017; 25(1):e2912.

3. Akre M, Finkelstein M, Erickson M, Liu M, et al. Sensitivity of the pediatric early warning score to identify patient deterioration. Pediatrics. 2010; 125(4):e763-9.

4. Oldroyd C, Day A. The use of pediatric early warning scores in the emergency department. J Emerg Nurs. 2011; 37(4):374-6.

5. Monaghan A. Detecting and managing deterioration in children. Paediatr Nurs. 2005; 17(1):32-5.

6. Gold DL, Mihalov LK, Cohen DM. Evaluating the pediatric early warning score (PEWS) system for admitted patients in the pediatric emergency department. Acad Emerg Med. 2014; 21(11):1249-56.

7. American Heart Association Staff, American Academy of
Pediatrics Staff. Pediatric Advanced Life Support Provider Manual. Dallas: Orora Visual; 2017.

8. Tucker KM, Brewer TL, Baker RB, Demeritt B, et al. Prospective evaluation of a pediatricinpatientearly warning scoring system. J Spec Pediatr Nurs. 2009; 14(2):79-85.

9. McElroy T,SwartzE,HassaniK, WaibelS, etal.Implementation study of a 5-component pediatric early warning system (PEWS) in an emergency department in British Columbia, Canada, to inform provincial scale up. BMC Emerg Med. 2019; 19(1):74.

10. Rosman SL, Karangwa V, Law M, Monuteaux M, et al. Provisional Validation of a Pediatric Early Warning Score for Resource-Limited Settings. Pediatrics. 2019; 143(5):e20183657.

11. Miranda JOF, Camargo CL, Sobrinho CLN, Portela DS, et al. Translation and adaptation of a pediatric early warning score. Rev Bras Enferm. 2016; 69(5):888-96.

12. Tume L. The deterioration of children in ward areas in a specialist children's hospital. Nurs Crit Care. 2007; 12(1): 12-9.

13. Parshuram CS, Bayliss A, Reimer J, Middaugh K, et al. Implementing the bedside paediatric early warning system in a community hospital: A prospectiveobservational study. Paediatr Child Health. 2011; 16(3):e18-22.

14. Urrutia LE. Comentario de "El puntaje es importante": amplias variaciones en el rendimiento predictivo de 18 sistemas de controles clínicos y alertas pediátricos. Arch Argent Pediatr 2017; 115(4):e265-7.

15. Iparraguirre A, Arzelan C, Barrionuevo L, Dobenau M, etal. Validación de un "Score" de Alerta Temprana en Pediatría. 1.erCongreso Argentino de Medicina Interna Pediátrica.Del 2 al 4 de noviembre de 2016. Ciudad Autónoma de Buenos Aires, Argentina. [Accessed on: June 1 1', 2020]. Available at: https: / / www.sap.org.ar/uploads/archivos / files trabajos-libres-congreso-de-medicina-interna_1482773674. pdf.

16. Chapman SM, Wray J, Oulton K, Pagel C, et al. "The Score Matters": wide variations in predictive performance of 18 paediatric track and trigger systems. Arch Dis Child. 2017; 102(6):487-495. 